\title{
TIBET A LUTA PELOS DIREITOS DE UMA CULTURA
}

No dia 09 de dezembro, às $10 \mathrm{~h} 00$, no Auditório XI de Agosto da Faculdade de Direito, deu-se início à Conferência "Tibet A Luta pelos Direitos de uma Cultura" cujo tema foi apresentado pelo professor Samdhong Rinpoche, presidente das Câmara dos Deputados do Governo do Tibet, no exílio.

A mesa de honra foi formada pelos professores Álvaro Villaça Azevedo, diretor da Faculdade de Direito da Universidade de São Paulo, e Dalmo de Abreu Dallari, professor da Faculdade de Direito e vice-presidente da Comissão Internacional de Juristas, pelo monsenhor Dario Bevilacqua, representante de Dom Paulo Evaristo Arns, cardeal arcebispo de São Paulo, pelo rabino Henry I. Sobel, presidente do Rabinato da Congregação Israelita de São Paulo; pelas coordenadoras da Rede Brasileira de Educação em Direitos Humanos e pela Rede Tibet da Anistia Internacional, Seção Brasileira, respectivamente professoras Margarida Genevois e Liana Verney.

A Conferência, ainda, foi apresentada por meio de convênio entre a Associação Palas Athenas do Brasil e a Faculdade de Direito da Universidade de São Paulo. 



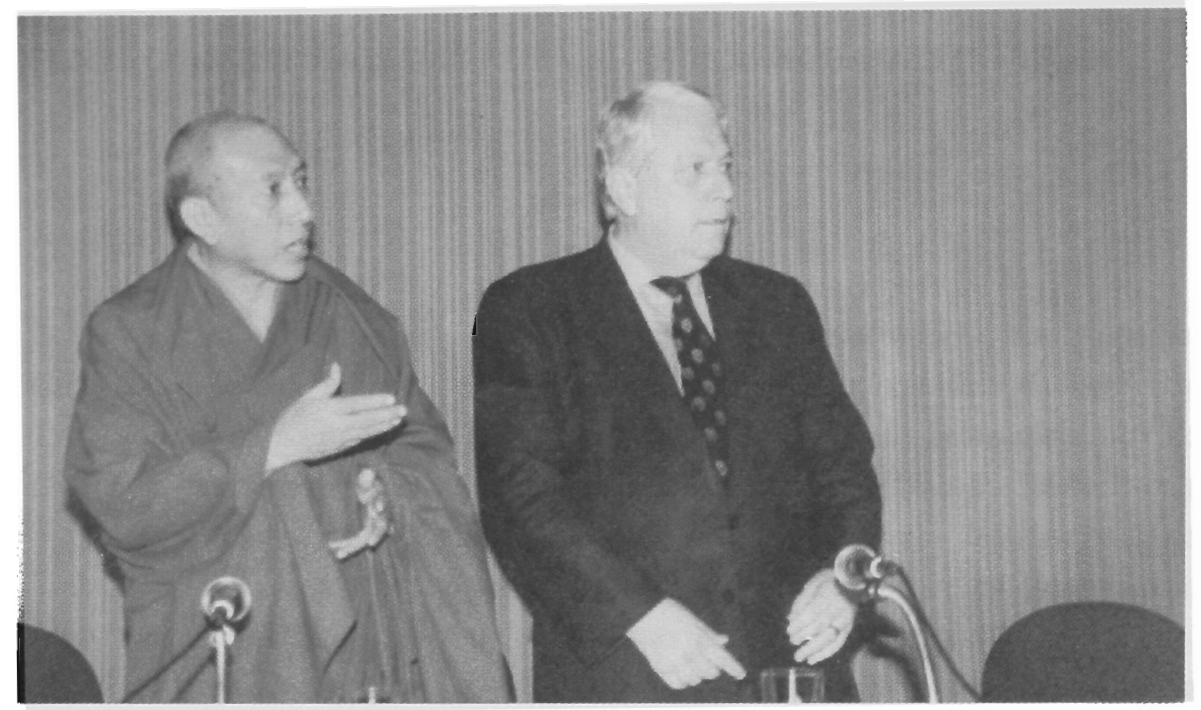

Os professores Samdhong Rinpoche e Álvaro Villaça Azevedo

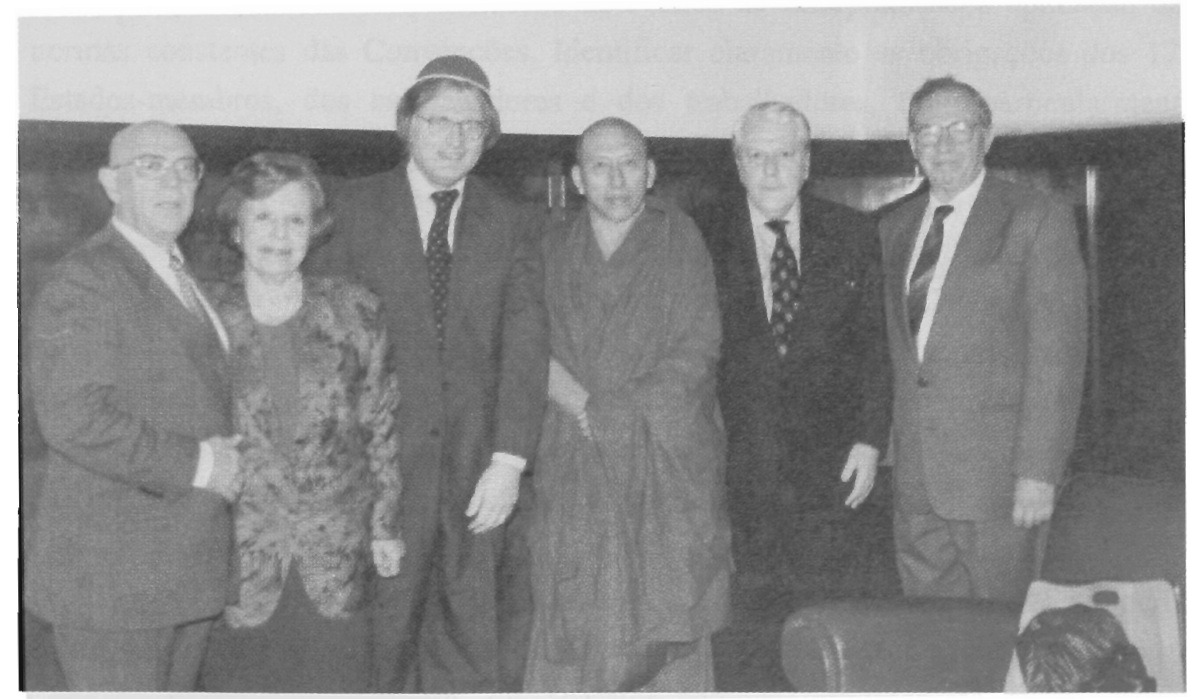

Da esq. à dir:: Dalmo Dallari, Margarida Genevois, Rabino Henry Sobel, Samdhong Rinpoche, Álvaro Azevedo e Monsenhor Dario Bevilaqua. 